\title{
Studi Penurunan Kadar Logam Besi (Fe) dan Logam Mangan (Mn) pada Lempung terhadap Perubahan Arus Listrik dalam Solenoida
}

\author{
Abdul Zain ${ }^{1, a}$, Arief Muliawan ${ }^{1, b}$ \\ ${ }^{1}$ Sekolah Tinggi Teknologi Bontang \\ JL. Ir H Juanda, No. 73 Rt. 36, Tanjung Laut, Kota Bontang, Kalimantan Timur 75321, Indonesia \\ jainbtg2013@gmail.com, ${ }^{\mathrm{b}}$ ariefstitek@gmail.com
}

\begin{abstract}
In the soil there are many compound of Fe and Mn as well as in the clay. Those two compounds need to be reduced to improve the resistive value of the clay. One method to reduce those compounds is by electromagnetic filter using solenoid. From the experiment circuit, it was found that the resistive value was $4.5 \mathrm{Ohm}$ with maximum current of 5 Ampere. Concentration of $\mathrm{Fe}$ and $\mathrm{Mn}$ after filtered were $0.46 \mathrm{ppm}$ and $0.40 \mathrm{ppm}$ respectively.
\end{abstract}

Keywords: Clay, Fe, Mn and Solenoid

\begin{abstract}
Abstrak- Dalam Tanah banyak terdapat senyawa Besi (Fe) dan Mangan (Mn), begitu pula pada tanah lempung. Kedua unsur ini perlu penurunan kadar sehingga sifat resistifitas dari bahan yang berbahan dasar lempung meningkat. Salah satu cara yang akan dilakukan dalam penurunan kadar ini dengan cara penyaringan elektromagnetik pada prinsip solenoida. Dari rangkaian diperoleh hambatan rangkaian sebesar 4,5 $\Omega$ dengan arus maksimum 5 ampere. Kadar Besi dan Mangan setelah dilakukan penyaringan sebesar 0,46 ppm dan 0,40 ppm.
\end{abstract}

Kata kunci : Lempung, besi, mangan, dan solenoida

\section{Pendahuluan}

Produk industri keramik dewasa ini semakin diminati oleh masyarakat. Hal ini terbukti dengan semakin luasnya pemakaian barang-barang keramik. Penggunaannya mulai dari peralatan rumah tangga yang sederhana hingga peralatan elektronika yang rumit untuk keperluan teknologi yang lebih mutakhir. Dengan perkembangannnya yang demikian jauh tersebut, diperlukan usaha-usaha untuk meningkatkan mutu bahan baku keramik.
Lempung dapat ditemukan diberbagai tempat di wilayah indonesia salah satunnya di Bontang. Pemanfatan lempung yang begitu besar bagi cadangan bahan baku ini kurang diimbangi dengan penggunaannya sebagai bahan baku keramik. Sejauh ini cadangan lempung tersebut baru digunakan sebagai bahan untuk pembuatan bata secara tradisional, pipa-pipa padat dan gerabah. Kenyataan ini membuat lempung Bontang kurang bernilai ekonomis tinggi. Hal ini dikarenakan kandungan $\mathrm{Fe}$ dalam lempung kaolinit tinggi (lebih dari $2 \%$ ), sehingga untuk bahan baku pembuatan keramik halus lempung kaolinit belum memenuhi syarat. Oleh sebab itu kandungan Fe dalam lempung kaolinit perlu diturunkan [1].

Air yang larut dalam lempung tentu mengandung Fe, dimana air tanah mengalami pencemaran. Berbagai usaha telah dilakukan agar pencemaran terhadap air dapat diminimalkan. Beberapa metode pengolahan air telah dilakukan baik secara fisika, kimia, maupun biologi. Pengolahan secara fisika antara lain dengan cara penyaringan (filtrasi), pemanasan, penyinaran ultraviolet, absorbsi dan adsorbsi. Sedangkan untuk pengolahan secara kimia antara lain dengan proses koagulasi dan aerasi, serta pengolahan secara biologi dengan menggunakan mikroorganisme tertentu untuk menurunkan kandungan logam berat [2].

Besi dan mangan merupakan komponen utama yang terdapat dalam lapisan kulit bumi dan sangat mudah telarut. Secara alamiah bentuk yang sangat umum ditemukan dalam air tanah adalah senyawa besi dan mangan. Air sebagai sarana pengolahan lempung tentu 
perlu disterilkan dari senyawa besi dan mangan. Hal ini memungkinkan pembuatan keramik isolator tanpa adanya unsur besi dan mangan.

Penelitian ini dilakukan berdasarkan permasalahan pengurangan kadar besi dan mangan dalam lempung. Penelitian ini merupakan pengolahan secara fisika yaitu dengan metode filtrasi menggunakan sistem penyaring elekromagnetik berdasarkan rangkaian solenoida. Metode ini dapat dijadikan salah satu metode alternatif yang efektif dan efisien untuk mengatasi permasalahan pengurangan unsur besi dan mangan dalam pembuatan keramik isolator. Untuk selanjutnya, penelitian ini diharapkan dapat memberikan manfaat bagi teknologi keramik .

\section{KAJIAN TEORI}

\section{a. Lempung}

Tanah lempung dihasilkan oleh alam, yang bersal dari pelapukan kerak bumi yang sebagian besar tersusun oleh batuan feldspatik, terdiri dari batuan granit dan batuan beku. Kerak bumi terdiri dari unsur unsur seperti silikon, oksigen, dan aluminium. Aktivitas panas bumi membuat pelapukan batuan silika oleh asam karbonat. kemudian membentuk terjadinya tanah liat. Tanah di alam mengandung besi (Fe) dan Mangan ( $\mathrm{Mn}$ ) yang terlarut dalam air tanah. Dalam prosesnya kedua unsur ini juga terlarut dalam lempung. Lempung kebanyakan dipergunakan dalam pembuatan keramik.

Lempung telah didefinisikan sebagai tanah yang menjadi koheren dan lengket bila dicampur dengan air. Ketika basah tanah ini mudah dibentuk, tetapi jika dikeringkan maka akan menjadi keras dan rapuh serta mempertahankan bentukny [3]. Lempung atau kermik memiliki sifat densitas, kuat patah maupun resistifitasnya. Sifat resistifitas yang tinggi mengakibatkan lempung dapat dimanfaatkan sebagai penahan aliran. Resistivitas listrik suatu bahan merupakan ukuran kemampuan bahan tersebut untuk men-transport muatan listrik di bawah pengaruh medan listrik [4].

\section{b. Filtrasi}

Filtrasi secara umum didefinisikan sebagai suatu proses pemisahan padatan yang terlarut dalam air. Filter berperan untuk memisahkan air dari partikel-partikel padatan. Di dalam filter diisi dengan bahan-bahan tertentu sebagai media filter. Media yang digunakan untuk bahan filter memiliki pori-pori dengan ukuran tertentu sesuai dengan ukuran padatan yang akan disaring dan tergantung pada sifat bahan yang akan difiltrasi. Media ini akan menahan semua partikel yang memiliki ukuran partikel yang lebih besar daripada pori-pori bahan filter [5].

Filtrasi yang baik ditentukan oleh daya filtrasinya yaitu banyaknya cairan yang menerobos per satuan waktu. Daya filtrasi tergantung pada faktor-faktor seperti luas permukaan filter, dimana semakin besar luas media filter, semakin besar pula daya filtrasinya. Selain itu beda tekanan antara kedua sisi media filter juga mempengaruhi daya filtrasi, tekanan yang tinggi dapat dicapai dengan memperbesar tekanan hidrostatik misalnya pengaliran dari tempat yang lebih tinggi. Faktor lain yang dapat memperbesar daya filtrasi adalah viskositas cairan dan tahanan media filter yang kecil, semakin tipis dan kasar media filter semakin besar daya filtrasinya [6].

\section{c. Solenoida}

Elektromagnetik merupakan sumber medan magnetik yang dihasilkan oleh arus listrik yang mengalir melalui sebuah kumparan. Agar dihasilkan medan magnetik yang kuat, kumparan diisi dengan bahan ferromagnetik, misalnya besi. Sistem penyaring elektromagnetik merupakan salah satu penerapan bahan ferromagnetik pada elektromagnet.

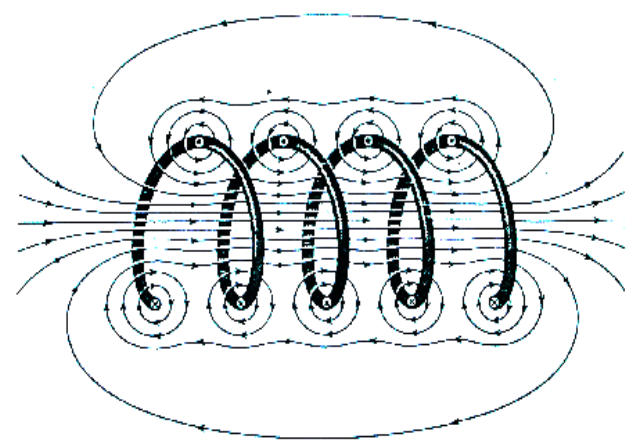

Gambar 1. Solenoida dengan lilitan yang sangat jarang [5]

Pada sistem penyaring elektromagnetik berupa kumparan yang dialiri arus listrik, di dalamnya diisi pasir besi sebagai media filter yang bertujuan untuk menimbulkan peristiwa magnetisasi bahan pada daerah di sekitar medan magnet. Sebuah solenoida yang dialiri arus akan menghasilkan medan magnet. Apabila dalam solenoida diberi bahan yang mudah termagnetisasi akan terjadi magnetisasi yang kuat. 


\section{Metode Penelitian}

a. Waktu penelitian terdiri dari lima tahap, yaitu :

1. Tahap persiapan alat-alat dan bahan penelitian, pembuatan rangkaian penyearah, pengujian awal peralatan, pembuatan sistem penyaring elektromagnetik dan pengujian alat.

2. Tahap pengambilan sampel (pengambilan lempung dan air sumur penduduk di Bontang)

3. Tahap proses pengambilan data

4. Tahap pengujian sampel hasil penelitian

5. Tahap analisis hasil penelitian dilakukan setelah diperoleh hasil pengujian sampel hasil penyaringan.

b. Tempat penelitian dilakukan yaitu :Persiapan alatalat, pembuatan sistem penyaring elektromagnetik, pengujian peralatan dan proses penyaringan dilakukan di Laboratorium Fisika Dasar, STITEK Bontang

c. Alat dan bahan yang digunakan dalam penelitian ini adalah :

1. Wadah penampung

2. Pipa kecil PVC

3. Kran air

4. Selang air

5. Pipa PVC, tutup pipa, sambungan pipa, dan penyambung pipa

6. Kawat tembaga

7. Rangkaian penyearah

8. Multimeter digital

9. Regulator

10. Teslameter

11. Tempat larutan sampel hasil penyaringan

12. Magnet batang

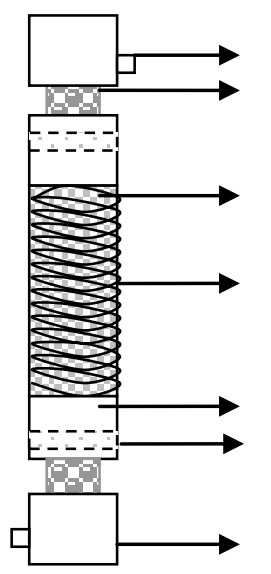

Keterangan :

1. Pipa kecil

2. Sambungan pipa, yang di dalamnya berisi busa penyaring

3. Pipa PVC yang diisi pasir besi

4. Solenoida

5. Penyambung pipa PVC

6. Penyaring dalam yang dibungkus kertas saring

7. Sambungan pipa PVC

Gambar 2. Skema penyaring elektromagnetik

d. Tahapan Penelitian

Tahapan penelitian yang akan dilakukan dalam hibah ini yakni:

1. Tahap Pertama Studi Pustaka dan Perencanaan kerja

2. Persiapan Alat dan bahan

3. Pembuatan rangkaian penyearah dilengkapi potensiometer dan dilakukan pengujian.

4. Pembuatan sistem penyaring

5. Pengujian awal alat dilakukan pada solenoida dengan mengukur hambatan solenoida.

6. Penyusunan rangkaian sistem penyaring

7. Pengujian Alat dengan tidak memastikan ada kebocoran saluran dan pengaturan debit aliran

8. Pengambilan sampel dan pencampuran yang mengandung $\mathrm{Fe}$ dan $\mathrm{Mn}$
9. Pengambilan data

10. Analisis data

\section{Hasil dan Pembahasan}

Pada pengujian perlatan penyaring elektromagnetik diperoleh hambatan dari penyaring sebesar 4,5 ohm ( $\Omega$ ) sedangkan kuat arus maksimum yang dihasilkan alat sebesar 5 ampere (A). Hasil pengukuran ditunjukan pada gambar 3 


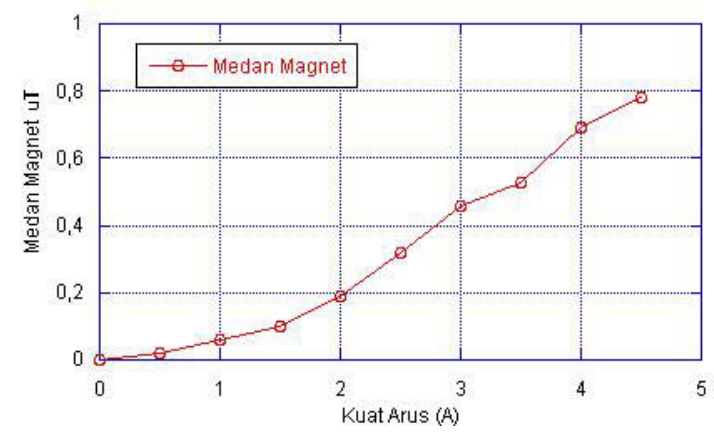

Gambar 3. Perubahan medan magnet terhadap kuat arus listrik

Dari data yang ada dapat didekati dengan pendekatan kurva dengan bentuk persamaan seperti yang ditunjukan pada gambar 4 .

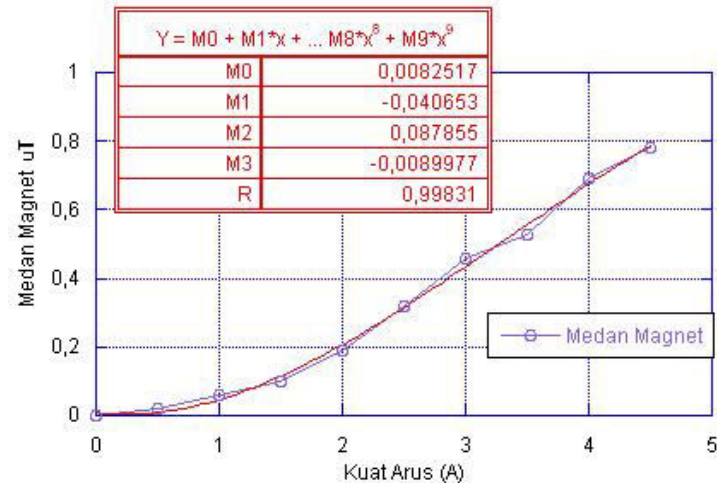

Gambar 4. Pendekatan kurva perubahan kuat arus

Perubahan kuat arus sangat mempengaruhi besarnya medan magnet. Makin besar arus yang diberikan maka makin besar pula medan magnet yang diperoleh.

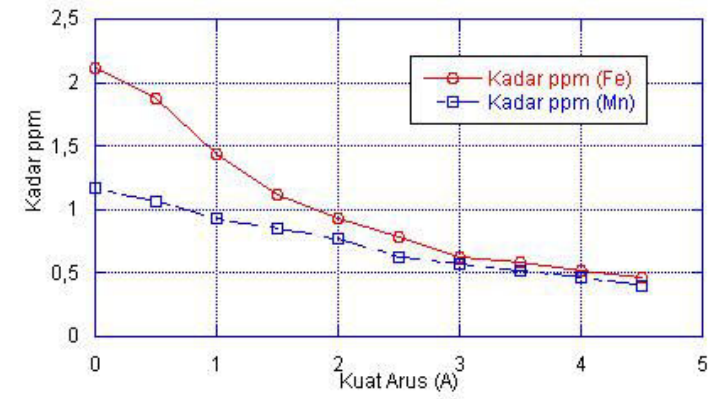

Gambar 5. Perubahan kadar ppm Fe dan Mn terhadap perubahan kuat arus

Dengan menambahkan kuat arus pada alat penyaring maka akan meningkatkan besarnya medan magnet. Hal ini menyebabkan efektivitas penyaring bertambah. Kadar ppm dari Fe dan Mn akan menurun bersamaan dengan peningkatan arus pada alat penyaring.

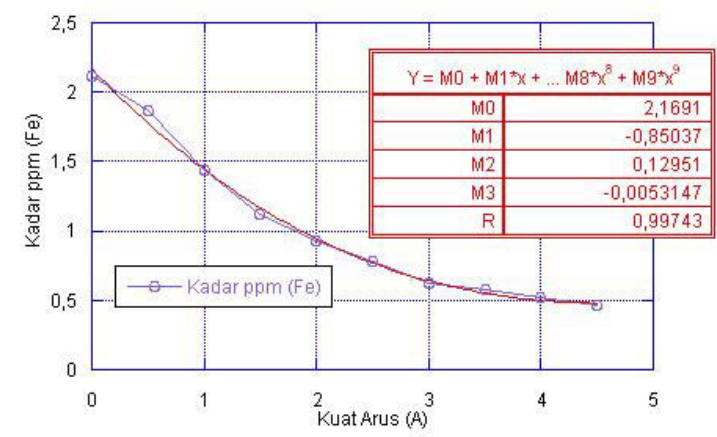

Gambar 6. Perubahan kadar ppm besi (Fe) terhadap arus

Pada awal pengukuran diperoleh kandungan ppm besi sebesar 2,12 ppm. Dengan menaikan arus hingga 4,5 ampere diperoleh penurunan kadar besi hingga $0,46 \mathrm{ppm}$. Sedangkan pada pengukuran awal kandungan mangan sebesar 1,17 ppm. Dengan meningkatkan arus hingga 4,5 ampere diperoleh kadar mangan hingga $0,40 \mathrm{ppm}$.

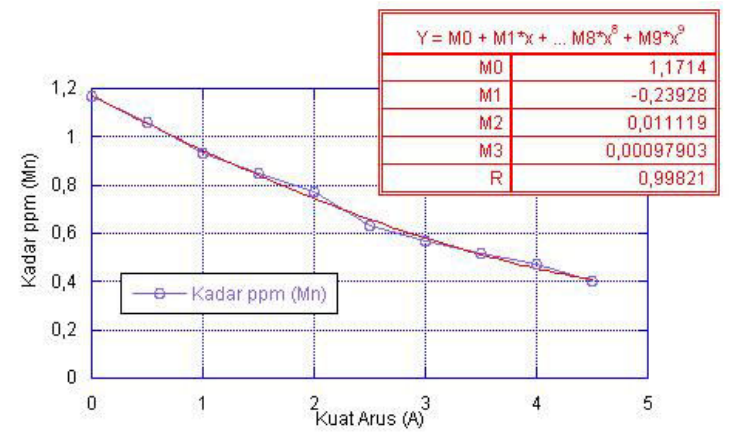

Gambar 7. Perubahan kadar ppm mangan (Mn) terhadap arus

\section{Kesimpulan}

Berdasarkan hasil yang diperoleh pada penelitian ini maka dapat disimpulkan bahwa:

1. Perubahan kuat arus akan mengakibatkan perubahan medan magnet

2. Kenaikan kuat arus listrik mengakibatkan kenaikan efektifitas penyaring dalam menurunkan kadar logam $\mathrm{Fe}$ dan logam Mn. 


\section{Daftar Pustaka}

[1] Subagya, P.H. Pengurangan kandungan Fe dalam Lempung Kaolinit dengan menggunakan asam florida. Sripsi, Universitas Diponegoro Semarang. 1997

[2] Alamsyah, S. Merakit Sendiri Alat Penjernih Air Untuk Rumah Tangga, Penerbit PT Kawan Pustaka, Jakarta. 2006
[3] McPhee, K. "An Introduction to Inorganic Dielectrics". IRE Transaction on Component Part. Vol.6 pp.3-33. 1959

[4] Haper,C.A. Handbook of Ceramics, glasses and diamonds"McGraw_Hill, USA. 2001

[5] Halliday, D. \& Resnick, R.. Pysics, Jilid 2, edisi tiga, terjemahan Silaban, \& Sucipto, E, Erlangga, Jakarta 1998.

[6] Bernasconi, G. Teknologi Kimia Bagian 2, PT Pradnya Paramita, Jakarta. 1995 